\title{
Treatment of Pituitary Carcinomas and Atypical Pituitary Adenomas: A Review
}

\author{
Toshio HIROHATA, ${ }^{1,2}$ Yudo IsHII, ${ }^{1}$ and Akira MATSUNO ${ }^{1}$ \\ ${ }^{1}$ Department of Neurosurgery, Teikyo University, Tokyo; \\ ${ }^{2}$ Department of Neurosurgery, The University of Tokyo, Tokyo
}

\begin{abstract}
Atypical pituitary adenomas (APAs) are aggressive tumors, harboring a Ki-67 (MIB-1) staining index of $3 \%$ or more, and positive immunohistochemical staining for $\mathrm{p53}$ protein, according to the World Health Organization (WHO) classification in 2004. Pituitary carcinomas (PC) usually develop from progressive APAs and predominantly consist of hormone-generating tumors, defined by the presence of disseminations in the cerebrospinal system or systemic metastases. Most of the cases with these malignant pituitary adenomas underwent surgeries, irradiations and adjuvant medical treatments, nevertheless, the therapies are mainly palliative. Recently, the efficacy of temozolomide (TMZ), an orally administered alkylating agent, has been reported as an alternative medical treatment. However, some recent studies have demonstrated a significant recurrence rate after effective response to TMZ. Further clinical and pathological researches of malignant pituitary adenomas will be required to improve the outcome of patients with these tumors.
\end{abstract}

Key words: atypical pituitary adenoma, pituitary carcinoma, temozolomide

\section{Introduction}

In 2004, the World Health Organization (WHO) developed a new classification for atypical pituitary adenomas (APAs) and pituitary carcinomas (PCs), based on their immunohistochemical markers and clinical behaviors. ${ }^{1)}$ Atypical adenomas are defined to have a Ki-67 (MIB-1) proliferation index of $3 \%$ or more, and extensive nuclear staining for p53 protein. Pituitary carcinomas are characterized by the above-mentioned biochemical features and the additional presence of cerebrospinal and/or systemic metastases (Fig. 1). APAs and PCs are resistant to conventional treatments. ${ }^{2-4)}$ Thapar et al. ${ }^{2}$ reported that the average rates of MIB-1 staining indices in non-invasive adenomas, invasive adenomas, and pituitary carcinomas were $1.37 \%, 4.66 \%, 11.91 \%$, respectively. The criterion that a Ki-67 (MiB-1) staining index is $3 \%$ or more was based on these findings. Meanwhile, some of APAs and PCs demonstrated the negative staining for p53 and/or MIB-1 staining indices less than 3\%, despite their malignant clinical courses.

In general, pituitary adenomas comprise an invasive adenoma frequently, which grows with

Received May 18, 2014; Accepted September 25, 2014 invasion into the floor of sella turcica, parasellar dura, and/or cavernous sinuses. The reported frequency of invasive pituitary adenomas ranges from $35 \%$ to nearly $50 \%{ }^{3,4)}$ The invasive adenomas have been distinguished from APAs.
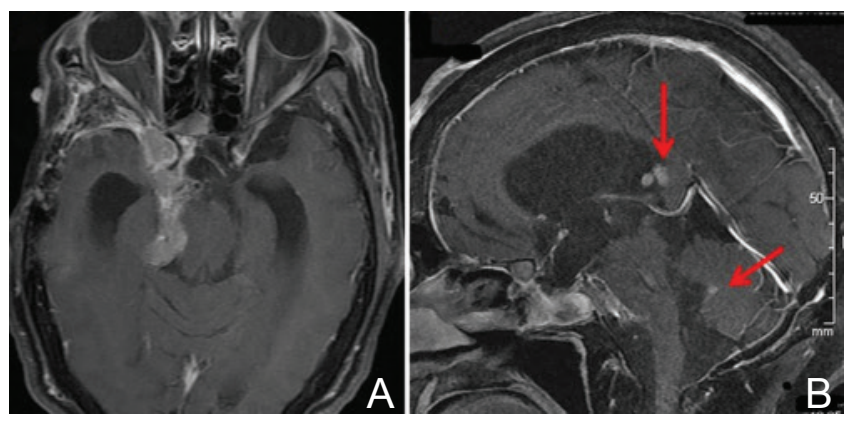

Fig. 1 A: MRI ( $\mathrm{T}_{1}$-weighted axial image with gadolinium enhancement) of a pituitary carcinoma. An invasive PRL-secreting pituitary tumor is demonstrated to progress into the right cavernous sinus, the middle and posterior fossa, and the ambient cistern. B: MRI ( $T_{1}$-weighted sagittal image with gadolinium enhancement) of the disseminated deposits. The disseminations of the tumor in the third and the fourth ventricles (arrows) are demonstrated, which proved to be a pituitary carcinoma. MRI: magnetic resonance imaging, PRL: prolactin. 


\section{Epidemiology and Clinical Features}

The incidence of atypical pituitary adenomas has not been determined precisely. Saeger et al. $(2007)^{4)}$ reported that $2.7 \%(12 / 457)$ of the cases with pituitary adenomas had been diagnosed as APAs. ${ }^{4)}$ Zada et al. reported that APAs accounted for 15\% (18/121) of the cases with pituitary adenomas. ${ }^{5}$ In the latter report, the authors mentioned that the frequency of APAs was overestimated because their hospital was a medical center for which a number of treatmentresistant cases have been applied.

Pituitary carcinoma occurs very rarely. The incidence of PCs has been reported as $0.12-0.2 \%$ of pituitary adenomas. ${ }^{4,6)}$ They have no difference in sex and in age distribution. In the literature, PCs consist largely of functioning (hormone-generating) adenomas. No PC cases are known to develop on a familial basis or to be accompanied with MEN-1 (multiple endocrine neoplasia type 1). Most of PC cases are preceded by aggressive clinical courses as APA in which they underwent surgeries, irradiation, and chemotherapies. In the event that an intrathecal dissemination or a distant metastasis was pointed out, the diagnosis of PC was determined. Sixty-six percent of the patients deceased within 1 year after the detection of metastatic lesions. ${ }^{6,7)}$ The mean survival period of PC patients was 2 years: 1 year for cases with systemic metastasis and 2.6 years for cases with intrathecal dissemination, respectively.

Zada et al. reported that $50 \%$ of APAs (9/18) were hormone-generating tumors, including five growth hormone (GH) secreting tumors, two adrenocorticotropic hormone (ACTH) secreting tumors, and two prolactin (PRL) secreting tumors. ${ }^{5)}$

In the review of the literature, most of PCs are hormone-generating adenomas, and ACTH- or PRLsecreting tumors are majorities in particular. ${ }^{7-9)}$ Eighty-eight percent of PCs were functioning tumors: $42 \%$ for ACTH secreting tumors, $33 \%$ for ACTH secreting tumors, $6 \%$ for $\mathrm{GH}$ secreting tumors, $5 \%$ for luteinizing hormone (LH) and/or follicle-stimulating hormone (FSH) secreting tumors, and 1\% for thyroidstimulating hormone (TSH) secreting tumors. ${ }^{8)}$

In the national survey for PCs and APAs by the Japan Society for Hypothalamic and Pituitary Tumors performed during 2010-2011, ${ }^{10)} 35$ cases of PCs consisted of 12 cases (34\%) of clinically non-functioning tumors, 11 cases $(31 \%)$ of ACTH secreting tumors, 5 cases (14\%) of PRL secreting tumors, 4 cases $(11 \%)$ of GH (including GH-PRL) secreting tumors, 1 case $(3 \%)$ of TSH secreting tumor, and 2 cases $(6 \%)$ of unknown subtype. In this report, the clinically non-functioning tumors are interpreted to include LH/FSH secreting tumors.

\section{Histological and Molecular Pathological Features}

Both APAs and PCs are characterized by mitoses of tumor cells, elevated levels of MIB-1 staining index, and positivity for p53 protein. These findings are useful in differentiating APAs and PCs from "typical" pituitary adenomas or invasive pituitary adenomas. ${ }^{2,5)}$ With regard to PCs, it was reported that they had relatively higher microvessel density than common pituitary adenomas. However, the nuclear atypicality, the elevated cell density, the presence of hemorrhage, and necrosis in tumors are not necessarily correlated with malignant grade. ${ }^{7)}$

In the diagnostic process of PCs, the metastatic lesion must be proved not to be derived from other tumors. Particularly, in the differential diagnosis from ectopic Cushing's syndrome, the presence or previous history of a pituitary adenoma should be confirmed. The immunohistochemical and/or ultra-structural findings are also useful in distinguishing between PCs and other metastatic tumors. In cases of hormonesecreting PCs, for example, the immunopositivity of systemic or disseminated lesions for the same pituitary hormone would attest the metastasis from the primary pituitary carcinoma. In addition, metastatic pituitary tumors (metastasis from other malignant tumors to the sella turcica) are discriminated from PCs. The conventional immunostaining markers would facilitate the diagnostic process. Pituitary adenomas usually demonstrate the immunopositivity for keratin and epithelial membrane antigen (EMA); the immunonegativity for S-100 protein, carcinoembryonic antigen (CEA), vimentin, neurofilament protein (NFP), and glial fibrillary acidic protein (GFAP).

\section{Treatment of PC and APA}

The cases with APAs are more likely to follow a clinically aggressive and invasive course. Zada et al. ${ }^{5)}$ reported 18 cases with APA, all of which underwent transsphenoidal surgeries (TSSs). Four cases of them had undergone precedent surgeries once or more. Sixteen cases (89\%) were invasive in intraoperative findings, and they had taken place invasions to parasellar regions and/or dura of the skull base. Cases with PRL-secreting adenomas had undergone precedent medical therapies with dopamine-agonist (cabergoline). One of the cases was a silent ACTH-secreting tumor which was treated with gamma knife surgery and proton therapy. Through TSSs, the total removal of the tumor was accomplished in 13 cases $(78 \%)$ and partially removed in 5 cases $(22 \%)$. In hormonegenerating tumors, $57 \%$ of them had improved 
endocrinologically through surgeries.

In case of PCs, metastases and/or disseminations have taken place already at the moment of diagnosis of PC, and therefore, treatment options for PCs are limited. The treatment of PCs is similar to that of invasive and progressive pituitary adenomas and includes surgeries (TSS and transcranial surgery), irradiations, and adjuvant medical treatment. ${ }^{8,9)}$

PCs are extensive and large tumors presenting perifocal mass effects which cause neurological symptoms, not only excessive hormone secretion of the tumor which causes systemic organ deficiency. Therefore, surgical resection can facilitate the reduction of mass effects and relieve neurological symptoms immediately. ${ }^{9)}$ However, it is unrealistic to carry out en bloc resection of the tumor in a surgery. When the tumor demonstrates extrasellar extension such as invasion to the cavernous sinus and progression into the middle or posterior cranial fossa, we should choose operative procedures including TSS, craniotomy, and sometimes combined surgery of both. ${ }^{11,12)}$

Radiotherapy has widely been used historically for precaution of tumor regrowth as a postoperative treatment, and for local control of metastatic lesions. ${ }^{13,14)}$ In the previous studies, irradiation was valid for local control at least temporarily, however, this treatment modality was less effective for the control after the tumor was proven as a PC. ${ }^{15-17)}$ Stereotactic radiosurgeries, including gamma-knife surgery, have the advantage that they can be applied to patients who have already had conventional radiotherapy and have developed a recurrent tumor or metastases. ${ }^{18)}$ However, experience with stereotactic radiosurgeries has been demonstrating only palliative effect in most cases. ${ }^{13,15,19)}$

Although most cases underwent surgical resections or irradiations for the metastatic lesions, they provided only palliative benefits and rarely maintained longterm remission. ${ }^{67}$ Several conventional regimens of chemotherapy had been reported, however, there were no randomized studies. In most cases with PC, the conventional chemotherapies are ineffective. ${ }^{14,20)}$ PRL-secreting PCs have mostly acquired resistance to dopamine-agonists. ${ }^{13)}$

Kaltsas et al. ${ }^{14)}$ reported seven patients; three with highly aggressive and four with malignant pituitary tumors, who received one or more courses of chemotherapy with lomustine and 5-fluorouracil. The survival period from the time of initiation of chemotherapy in patients with malignant tumors ranged from 3 months to 65 months. All patients with metastatic tumors eventually died.

With regard to poorly differentiated neuroendocrine tumors exhibiting high proliferative indices, it was demonstrated that chemotherapy in combination of cis-platinum and etoposide might be associated with considerable response. ${ }^{14,21)}$

Some retrospective data on the use of chemotherapy in PCs with systemic metastases have showed that conventional chemotherapy may prolong the patients' survival, but not be curative..$^{9,13,14)}$ In recent years, the efficacy of temozolomide (TMZ, Merck \& Co., Inc., New Jersey, USA) treatment for malignant pituitary tumors has been reported. The following section focuses on TMZ treatment for PCs and APAs.

\section{TMZ Treatment for PC and APA}

TMZ is a second-generation alkylating agent, which induces gene damage and inhibits deoxyribonucleic acid (DNA) transcription with alkylation at the $\mathrm{O} 6$ position of guanine bases. TMZ has been widely applied in the treatment of glioblastoma. The O6-methyl-guanine-DNA methyltransferase (MGMT) is a DNA repair system, which represents the important mechanism of resistance to TMZ through repairing an alkylated guanine of DNA. ${ }^{22}$

Regarding malignant pituitary tumors treated with TMZ, 24 case reports of PC and 27 case reports of APA were reported in the literature from 2006 to 2012. ${ }^{23-49)} \mathrm{TMZ}$ was administered mainly according to the standard therapeutic dose of $150-200 \mathrm{mg} / \mathrm{m}^{2}$ daily for 5 of every 28 days as one cycle. ${ }^{50)}$ In these reports, TMZ was effective in 36 cases $(71 \%)$ and ineffective in 15 cases (29\%). It was implied that limited cases, treated successfully, were reported in the earlier years, and the results were biased toward the better.

Bush et al. ${ }^{41)}$ reported seven consecutive cases treated with TMZ; effective in five cases $(71 \%)$. Raverot et al. ${ }^{43)}$ reported eight consecutive cases treated with TMZ; effective in three cases (38\%), and Losa et al. ${ }^{44}$ reported six consecutive cases treated with TMZ; effective in four cases (67\%). The mean response rate was $57 \%(12 / 21)$.

In the reported TMZ-responsive tumors, the clinical response is rapid and is associated with decreased mass effects. In the patients with functioning tumors, an immediate reduction in serum hormone values became apparent after the administration of TMZ. ${ }^{51)}$ In the morphologic and histological findings, the TMZ-treated tumors were reported that had tendency to differentiation and a lower MIB-1 staining index, hemorrhage, necrosis, focal fibrosis and neuronal transformation. ${ }^{(24,25)}$ These changes had resulted in softening and friability during surgery. Low-level MGMT immunoexpression was correlated with a favorable response. ${ }^{43,51)}$ However, no remarkable 
association was found between MGMT promoter methylation and the response to TMZ treatment. ${ }^{41,51)}$

In the national research of the Japan Society for Hypothalamic and Pituitary Tumors, ${ }^{10)}$ the clinical and pathological findings of 13 cases of APAs and PCs treated with TMZ were reported. In that study, although 10 cases $(77 \%)$ responded to TMZ completely or partially, 6 cases (46\%) became recurrent after a response to TMZ. The mean period that the tumors acquired resistance after the initiation of TMZ was 10.5 months, ranged from 5 months to 19 months. In this report, MGMT immunoexpression had no remarkable relation with the response to TMZ.

In literature, the long-term outcomes of 13 PC cases after TMZ treatment, which responded to TMZ initially, were reported. ${ }^{52)}$ Seven patients were considered as stable, 6-34 months after the cessation of tumor growth (median, 16 months). Six patients became recurrent, 4-15 months after the cessation (median, 9 months).

We demonstrated that the immunoexpression of MSH6 had correlated significantly with TMZ efficacy. ${ }^{10,45,53)}$ The mismatch repair (MMR) pathway plays important roles in the removal and maintenance of DNA base mismatches caused by incorrect insertions or deletions arising from DNA replication. In MMR pathway, base mismatches are detected by the heterodimers of MSH2 and MSH6, which assist another heterodimeric complex of MLH1 and PMS2. ${ }^{54)}$ Unrepaired TMZ-induced O6-methyl-guanine (MeG) can pair with cytosine (C) or thymidine (T) and the nucleotide pair of O6-MeG/C or O6-MeG/T is detected by the MMR system. Keeping O6-MeG intact, only newly synthesized strands are excised, and this repair cycle will be repeated. With this useless cycle, MMR pathway stimulates DNA damage-induced G2 checkpoint and apoptosis during DNA synthesis. Therefore, it was suggested that the inactivation of MMR is associated with tolerance to the cytotoxic effects of alkylating agents. ${ }^{55,56)}$

Based on the published cases and studies, it was reported that low MGMT and positive MSH6 immunoexpression had positive correlation with the response to TMZ in the treatment of APAs and PCs. Raverot et al. proposed that response after three cycles of TMZ treatment was a predictor of TMZ effectiveness. ${ }^{43)}$ However, other reliable predictors of TMZ treatment efficacy have not been revealed in clinical profiles or pathological findings of the subjects. Ortiz et al. suggested that TMZ therapy can be recommended when other therapeutic options fail in aggressive pituitary adenomas and pituitary carcinomas exhibiting continued growth after repeated surgeries, radiotherapy, and drug therapy. ${ }^{57)}$
For one instance, we present a case of a patient with PC (Figs. 1, 2). ${ }^{45)}$ A 60 -year-old woman with atypical prolactinoma had undergone multiple therapies for 7 years, including dopamine-agonists, surgical resections (5 times), conventional irradiation, and gamma knife surgery. Ten cycles of TMZ therapy, $200 \mathrm{mg} / \mathrm{m}^{2}$ for 5 days every 4 weeks, caused tumor shrinkage, decrease of serum prolactin levels, and improvement of her neurological symptoms. Six months after discontinuation of TMZ, the tumor became recurrent with local tumor regrowth and intraventricular disseminations (Fig. 1), which proved to be pituitary carcinoma. The tumor had acquired resistance against TMZ at that time. A sixth surgery and adjuvant chemotherapies were ineffective, and the patient deceased 9 years after the first diagnosis of APA. The pathological findings of the tumor specimen resected by the sixth surgery demonstrated atypical nuclei, mitoses, high Ki-67 labeling index (18\%), and immunopositivity for prolactin and p53 protein (Fig. 2). In this case, MGMT was immunonegative in the tumor specimens throughout her clinical course. Although MSH6 was diffusely immunopositive in the atypical adenoma, it became immunonegative when the tumor recurred as TMZ-resistant pituitary carcinoma.

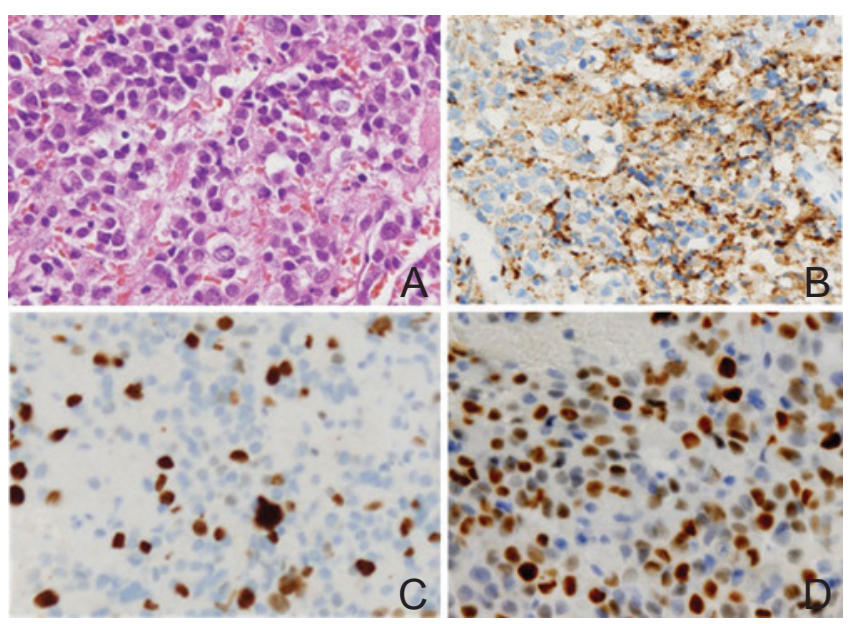

Fig. 2 Pathological findings of the resected specimens of a PRL-secreting pituitary carcinoma. A: The hematoxylin-eosin staining (original magnification; $\times 200$ ) shows highly dense tumor cells, affluent stromal microvessels, atypical nuclei, and mitoses. B: Immunohistochemistry (IHC) for PRL (original magnification; $\times 200$ ) shows diffuse immunopositivity. C: IHC for Ki-67 (original magnification; $\times 200$ ) shows $18 \%$ labeling index, representing a remarkably higher MIB-1 index than typical pituitary adenomas. D: IHC for p53 protein (original magnification; $\times 200$ ) shows approximately $50 \%$ LI, designated as an atypical pituitary adenoma or a pituitary carcinoma. LI: labeling index, PRL: prolactin. 


\section{Alternative Treatments for TMZ-Resistant Pitui- tary Tumors}

Several different treatments for TMZ-resistant PCs and APAs have been sought recently. Some case reports suggested that other chemotherapeutic agents were useful in combination with TMZ.

Thearle et al. $^{37)}$ reported a case with an aggressive corticotroph pituitary tumor treated with TMZ and capecitabine. In this case, although the tumor decreased remarkably in size and serum ACTH levels, the tumor recurred after 5 months harboring a more malignant phenotype.

Bode et al..$^{39)}$ reported a case with an ACTH-secreting pituitary carcinoma complicated with widespread intracranial and systemic metastases, and treated with TMZ and pasireotide (SOM230, Novartis, Basel, Switzerland). A sustained tumor control was achieved for 12 months in combination with TMZ and pasireotide, and for more than 9 months on monotherapy with pasireotide.

$\mathrm{PI} 3 \mathrm{~K} / \mathrm{Akt} / \mathrm{mTOR}$ signaling is up-regulated in pituitary tumors ${ }^{58)}$ and the anti-tumoral effect of mTOR inhibitor, everolimus (Novartis, Basel, Switzerland), on pituitary cell lines or primary cultures has been demonstrated in vitro. ${ }^{59,60)}$ Jouanneau et al. ${ }^{61)}$ reported an ACTH-secreting pituitary carcinoma treated in combination of everolimus and octreotide. Unfortunately, this combined therapy did not achieve to control neither tumor growth nor ACTH secretion.

Anti-angiogenic therapy was also attempted in the treatment of malignant pituitary tumors. Ortiz et $a l .{ }^{47}$ reported a case with an aggressive silent corticotroph adenoma, progressing to carcinoma after TMZ administration. Anti-vascular endothelial growth factor (VEGF, bevacizumab, Roche, Base, Switzerland) therapy was induced, and long-term (26 months) control of the tumor was achieved.

In addition, the role of the epidermal growth factor receptor (EGFR) pathway was reported in growth regulation of pituitary adenomas, and EGFR is regarded as a potential therapeutic target with tyrosine kinase inhibitors. ${ }^{62,63)}$

However malignant pituitary adenomas occur infrequently, we may have to consider alternative therapeutic options along with existing adjuvant therapies in combination with surgeries, radiotherapy, and TMZ.

\section{Conclusion}

Pituitary carcinomas mainly develop from aggressive or atypical pituitary adenomas, harboring elevated proliferative rates and mutant p53 protein. Although most cases with PC underwent multimodality treatments, including transsphenoidal and/ or transcranial surgeries, radiotherapy and diversified conventional chemotherapy, these therapeutic procedures are usually palliative. On the basis of the recent findings, TMZ, an alkylating agent, is a potential and alternative treatment for PCs. The low MGMT immunoexpression and the preserved MSH6 immunoexpression are positively correlated with therapeutic response to TMZ. However, through the course of TMZ treatment, PCs acquire resistance against TMZ at a high rate. Because of the rarity of APAs and PCs, the small number of available subjects is the limitation of the studies for malignant pituitary adenomas. Multi-institutional clinical and basic researches to assess optimal regimens are necessary.

\section{Conflicts of Interest Disclosure}

The authors have no conflicts of interest and no financial support to be disclosed.

\section{References}

1) Lloyd RV, Kovacs K, Young WF Jr, Farrel WE, Asa SL, Truillas J, Kontogeorgos G, Sano T, Scheithauer BW, Horvath E, DeLellis RA, Heitz PU: Pituitary tumors, in DeLellis R, Lloyd RV, Heitz PV, Eng C (eds): Introduction. WHO Classification of Tumors of the Endocrine Organs: Pathology and Genetics of Endocrine Organs. Lyon, IARC Press, 2004, pp 10-13

2) Thapar K, Kovacs K, Scheithauer BW, Stefaneanu L, Horvath E, Pernicone PJ, Murray D, Laws ER Jr: Proliferative activity and invasiveness among pituitary adenomas and carcinomas: an analysis using the MIB-1 antibody. Neurosurgery 38: 9-106; discussion 106-107, 1996

3) Scheithauer BW, Kovacs KT, Laws ER, Randall RV: Pathology of invasive pituitary tumors with special reference to functional classification. J Neurosurg 65: 733-744, 1986

4) Saeger W, Lüdecke DK, Buchfelder M, Fahlbusch R, Quabbe HJ, Petersenn S: Pathohistological classification of pituitary tumors: 10 years of experience with the German Pituitary Tumor Registry. Eur J Endocrinol 156: 203-216, 2007

5) Zada G, Woodmansee WW, Ramkissoon S, Amadio J, Nose V, Laws ER: Atypical pituitary adenomas: incidence, clinical characteristics, and implications. J Neurosurg 114: 336-344, 2011

6) Pernicone PJ, Scheithauer BW, Sebo TJ, Kovacs KT, Horvath E, Young WF, Lloyd RV, Davis DH, Guthrie BL, Schoene WC: Pituitary carcinoma: a clinicopathologic study of 15 cases. Cancer 79: 804-812, 1997

7) Scheithauer BW, Kurtkaya-Yapicier O, Kovacs KT, Young WF, Lloyd RV: Pituitary carcinoma: a clinicopathological review. Neurosurgery 56: 1066-1074; discussion 1066-1074, 2005

Neurol Med Chir (Tokyo) 54, December, 2014 
8) Ragel BT, Couldwell WT: Pituitary carcinoma: a review of the literature. Neurosurg Focus 16: E7, 2004

9) Kaltsas GA, Nomikos P, Kontogeorgos G, Buchfelder M, Grossman AB: Clinical review: Diagnosis and management of pituitary carcinomas. J Clin Endocrinol Metab 90: 3089-3099, 2005

10) Hirohata T, Asano K, Ogawa Y, Takano S, Amano K, Isozaki O, Iwai Y, Sakata K, Fukuhara N, Nishioka H, Yamada S, Fujio S, Arita K, Takano K, Tominaga A, Hizuka N, Ikeda H, Osamura RY, Tahara S, Ishii Y, Kawamata T, Shimatsu A, Teramoto A, Matsuno A: DNA mismatch repair protein (MSH6) correlated with the responses of atypical pituitary adenomas and pituitary carcinomas to temozolomide: the national cooperative study by the Japan Society for Hypothalamic and Pituitary Tumors. J Clin Endocrinol Metab 98: 1130-1136, 2013

11) Tamiya T: Surgical procedures for giant pituitary tumors, in Yamaura A (ed): Brain Tumors II, Noshinkeigeka Taikei, the 1st edition. Tokyo, Nakayama Shoten, 2004, pp 309-323 (Japanese)

12) Yamada S, Ohyama K, Fukuhara N: Choice of operative procedures of transsphenoidal surgery: approaches for the combined surgery with craniotomy. Folia Endocrinogica Japonica 82(Supple): 37-39, 2006 (Japanese)

13) Kaltsas GA, Grossman AB: Malignant pituitary tumours. Pituitary 1: 69-81, 1998

14) Kaltsas GA, Mukherjee JJ, Plowman PN, Monson JP, Grossman AB, Besser GM: The role of cytotoxic chemotherapy in the management of aggressive and malignant pituitary tumors. J Clin Endocrinol Metab 83: 4233-4238, 1998

15) Cartwright DM, Miller TR, Nasr AJ: Fine-needle aspiration biopsy of pituitary carcinoma with cervical lymph node metastases: a report of two cases and review of the literature. Diagn Cytopathol 11: 68-73, 1994

16) Wilson DF: Pituitary carcinoma occurring as middle ear tumor. Otolaryngol Head Neck Surg 90: 665-666, 1982

17) Garrão AF, Sobrinho LG, Pedro-Oliveira, Bugalho MJ, Boavida JM, Raposo JF, Loureiro M, Limbert E, Costa I, Antunes JL: ACTH-producing carcinoma of the pituitary with haematogenic metastases. Eur J Endocrinol 137: 176-180, 1997

18) Swords FM, Allan CA, Plowman PN, Sibtain A, Evanson J, Chew SL, Grossman AB, Besser GM, Monson JP: Stereotactic radiosurgery XVI: a treatment for previously irradiated pituitary adenomas. J Clin Endocrinol Metab 88: 5334-5340, 2003

19) Gaffey TA, Scheithauer BW, Lloyd RV, Burger PC, Robbins P, Fereidooni F, Horvath E, Kovacs K, Kuroki T, Young WF Jr, Sebo TJ, Riehle DL, Belzberg AJ: Corticotroph carcinoma of the pituitary: a clinicopathological study. Report of four cases. J Neurosurg 96(2): 352-360, 2002

20) Walker JD, Grossman A, Anderson JV, Ur E, Trainer PJ, Benn J, Lowy C, Sönksen PH, Plowman PN, Lowe DG: Malignant prolactinoma with extracranial metastases: a report of three cases. Clin Endocrinol (Oxf) 38: 411-419, 1993

21) Kaltsas GA, Besser GM, Grossman AB: The diagnosis and medical management of advanced neuroendocrine tumors. Endocr Rev 25: 458-511, 2004

22) Hegi ME, Diserens AC, Gorlia T, Hamou MF, de Tribolet N, Weller M, Kros JM, Hainfellner JA, Mason W, Mariani L, Bromberg JE, Hau P, Mirimanoff RO, Cairncross JG, Janzer RC, Stupp R: MGMT gene silencing and benefit from temozolomide in glioblastoma. N Engl J Med 352: 997-1003, 2005

23) Lim S, Shahinian H, Maya MM, Yong W, Heaney AP: Temozolomide: a novel treatment for pituitary carcinoma. Lancet Oncol 7: 518-520, 2006

24) Syro LV, Uribe H, Penagos LC, Ortiz LD, Fadul CE, Horvath E, Kovacs K: Antitumour effects of temozolomide in a man with a large, invasive prolactinproducing pituitary neoplasm. Clin Endocrinol ( $\mathrm{Oxf}$ ) 65: 552-553, 2006

25) Kovacs K, Horvath E, Syro LV, Uribe H, Penagos LC, Ortiz LD, Fadul CE: Temozolomide therapy in a man with an aggressive prolactin-secreting pituitary neoplasm: Morphological findings. Hum Pathol 38: 185-189, 2007

26) Fadul CE, Kominsky AL, Meyer LP, Kingman LS, Kinlaw WB, Rhodes CH, Eskey CJ, Simmons NE: Long-term response of pituitary carcinoma to temozolomide. Report of two cases. J Neurosurg 105: 621-626, 2006

27) Neff LM, Weil M, Cole A, Hedges TR, Shucart W, Lawrence D, Zhu JJ, Tischler AS, Lechan RM: Temozolomide in the treatment of an invasive prolactinoma resistant to dopamine agonists. Pituitary 10: 81-86, 2007

28) McCormack AI, McDonald KL, Gill AJ, Clark SJ, Burt MG, Campbell KA, Braund WJ, Little NS, Cook RJ, Grossman AB, Robinson BG, Clifton-Bligh RJ: Low O6-methylguanine-DNA methyltransferase (MGMT) expression and response to temozolomide in aggressive pituitary tumours. Clin Endocrinol (Oxf) 71: 226-233, 2009

29) Guzel A, Tatli M, Senturk S, Guzel E, Cayli SR, Sav A: Pituitary carcinoma presenting with multiple metastases: case report. J Child Neurol 23: 1467-1471, 2008

30) Debono M, Bridgewater C, Ross R, Newell-Price J: Treating an aggressive prolactinoma in a patient with MEN 1: beneficial response totemozolomide. Society for Endocrinology BES. Endocrine Abstracts 15: 188,2008

31) Mohammed S, Kovacs K, Mason W, Smyth H, Cusimano MD: Use of temozolomide in aggressive pituitary tumors: case report. Neurosurgery 64(4): E773-E774; discussion E774, 2009

32) Byrne S, Karapetis C, Vrodos N: A novel use of temozolomide in a patient with malignant prolactinoma. J Clin Neurosci 16: 1694-1696, 2009

33) Hagen C, Schroeder HD, Hansen S, Hagen C, Andersen M: Temozolomide treatment of a pituitary carcinoma and two pituitary macroadenomas 
resistant to conventional therapy. Eur J Endocrinol 161: 631-637, 2009

34) Takeshita A, Inoshita N, Taguchi M, Okuda C, Fukuhara N, Oyama K, Ohashi K, Sano T, Takeuchi Y, Yamada S: High incidence of low O(6)methylguanine DNA methyltransferase expression in invasive macroadenomas of Cushing's disease. Eur J Endocrinol 161: 553-559, 2009

35) Moyes VJ, Alusi G, Sabin HI, Evanson J, Berney DM, Kovacs K, Monson JP, Plowman PN, Drake WM: Treatment of Nelson's syndrome with temozolomide. Eur J Endocrinol 160: 115-119, 2009

36) Syro LV, Scheithauer BW, Ortiz LD, Fadul CE, Horvath E, Rotondo F, Kovacs K: Effect of temozolomide in a patient with recurring oncocytic gonadotrophic pituitary adenoma. Hormones (Athens) 8: 303-306, 2009

37) Thearle MS, Freda PU, Bruce JN, Isaacson SR, Lee Y, Fine RL: Temozolomide (Temodar ${ }^{\circledR}$ ) and capecitabine $\left(\right.$ Xeloda $^{\circledR}$ ) treatment of an aggressive corticotroph pituitary tumor. Pituitary 14: 418-424, 2011

38) Morin E, Berthelet F, Weisnagel J, Bidlingmaier M, Serri O: Failure of temozolomide and conventional doses of pegvisomant to attain biochemical control in a severe case of acromegaly. Pituitary 15: 97-100, 2012

39) Bode H, Seiz M, Lammert A, Brockmann MA, Back W, Hammes HP, Thomé C: SOM230 (pasireotide) and temozolomide achieve sustained control of tumour progression and ACTH secretion in pituitary carcinoma with widespread metastases. Exp Clin Endocrinol Diabetes 118: 760-763, 2010

40) Dillard TH, Gultekin SH, Delashaw JB, Yedinak CG, Neuwelt EA, Fleseriu M: Temozolomide for corticotroph pituitary adenomas refractory to standard therapy. Pituitary 14: 80-91, 2011

41) Bush ZM, Longtine JA, Cunningham T, Schiff D, Jane JA, Vance ML, Thorner MO, Laws ER, Lopes MB: Temozolomide treatment for aggressive pituitary tumors: correlation of clinical outcome with $\mathrm{O}(6)-$ methylguanine methyltransferase (MGMT) promoter methylation and expression. J Clin Endocrinol Metab 95: E280-E290, 2010

42) Curtò L, Torre ML, Ferraù F, Pitini V, Altavilla G, Granata F, Longo M, Hofland LJ, Trimarchi F, Cannavò S: Temozolomide-induced shrinkage of a pituitary carcinoma causing Cushing's disease-report of a case and literature review. Scientific World Journal 10: 2132-2138, 2010

43) Raverot G, Sturm N, de Fraipont F, Muller M, Salenave S, Caron P, Chabre O, Chanson P, CortetRudelli C, Assaker R, Dufour H, Gaillard S, François P, Jouanneau E, Passagia JG, Bernier M, Cornélius A, Figarella-Branger D, Trouillas J, Borson-Chazot F, Brue T: Temozolomide treatment in aggressive pituitary tumors and pituitary carcinomas: a French multicenter experience. J Clin Endocrinol Metab 95: 4592-4599, 2010

44) Losa M, Mazza E, Terreni MR, McCormack A, Gill AJ, Motta M, Cangi MG, Talarico A, Mortini P, Reni
M: Salvage therapy with temozolomide in patients with aggressive or metastatic pituitary adenomas: experience in six cases. Eur $J$ Endocrinol 163: 843-851, 2010

45) Murakami M, Mizutani A, Asano S, Katakami H, Ozawa Y, Yamazaki K, Ishida Y, Takano K, Okinaga $\mathrm{H}$, Matsuno A: A mechanism of acquiring temozolomide resistance during transformation of atypical prolactinoma into prolactin-producing pituitary carcinoma: case report. Neurosurgery 68: E1761E1767; discussion E1767, 2011

46) Moshkin O, Syro LV, Scheithauer BW, Ortiz LD, Fadul CE, Uribe H, Gonzalez R, Cusimano M, Horvath E, Rotondo F, Kovacs K: Aggressive silent corticotroph adenoma progressing to pituitary carcinoma: the role of temozolomide therapy. Hormones (Athens) 10: 162-167, 2011

47) Ortiz LD, Syro LV, Scheithauer BW, Ersen A, Uribe H, Fadul CE, Rotondo F, Horvath E, Kovacs K: AntiVEGF therapy in pituitary carcinoma. Pituitary 15: 445-449, 2012

48) Annamalai AK, Dean AF, Kandasamy N, Kovacs K, Burton H, Halsall DJ, Shaw AS, Antoun NM, Cheow HK, Kirollos RW, Pickard JD, Simpson HL, Jefferies SJ, Burnet NG, Gurnell M: Temozolomide responsiveness in aggressive corticotroph tumours: a case report and review of the literature. Pituitary 15: 276-287, 2012

49) Arnold PM, Ratnasingam D, O’Neil MF, Johnson PL: Pituitary carcinoma recurrent to the lumbar intradural extramedullary space: case report. J Spinal Cord Med 35: 118-121, 2012

50) Ekeblad S, Sundin A, Janson ET, Welin S, Granberg D, Kindmark H, Dunder K, Kozlovacki G, Orlefors H, Sigurd M, Oberg K, Eriksson B, Skogseid B: Temozolomide as monotherapy is effective in treatment of advanced malignant neuroendocrine tumors. Clin Cancer Res 13: 2986-2991, 2007

51) Syro LV, Ortiz LD, Scheithauer BW, Lloyd R, Lau Q, Gonzalez R, Uribe H, Cusimano M, Kovacs K, Horvath E: Treatment of pituitary neoplasms with temozolomide: a review. Cancer 117: 454-462, 2011

52) Raverot G, Castinetti F, Jouanneau E, Morange I, Figarella-Branger D, Dufour H, Trouillas J, Brue T: Pituitary carcinomas and aggressive pituitary tumours: merits and pitfalls of temozolomide treatment. Clin Endocrinol (Oxf) 76: 769-775, 2012

53) Matsuno A, Murakami M, Hoya K, Yamada SM, Miyamoto S, Yamada S, Son JH, Nishido H, Ide F, Nagashima H, Sugaya M, Hirohata T, Mizutani A, Okinaga H, Ishii Y, Tahara S, Teramoto A, Osamura RY: Molecular status of pituitary carcinoma and atypical adenoma that contributes the effectiveness of temozolomide. Med Mol Morphol 47: 1-7, 2014

54) Stojic L, Mojas N, Cejka P, Di Pietro M, Ferrari S, Marra G, Jiricny J: Mismatch repair-dependent G2 checkpoint induced by low doses of SN1 type methylating agents requires the ATR kinase. Genes Dev 18: 1331-1344, 2004 
55) Friedman HS, Johnson SP, Dong Q, Schold SC, Rasheed BKA, Bigner SH, Ali-Osman F, Dolan E, Colvin OM, Houghton P, Germain G, Drummond JT, Keir S, Marcelli S, Bigner DD, Modrich P: Methylator resistance mediated by mismatch repair deficiency in a glioblastoma multiforme xenograft. Cancer Res 57: 2933-2936, 1997

56) Kinsella TJ: Coordination of DNA mismatch repair and base excision repair processing of chemotherapy and radiation damage for targeting resistant cancers. Clin Cancer Res 15: 1853-1859, 2009

57) Ortiz LD, Syro LV, Scheithauer BW, Rotondo F, Uribe H, Fadul CE, Horvath E, Kovacs K: Temozolomide in aggressive pituitary adenomas and carcinomas. Clinics (Sao Paulo) 67 Suppl 1: 119-123, 2012

58) Dworakowska D, Wlodek E, Leontiou CA, Igreja S, Cakir M, Teng M, Prodromou N, Goth MI, Grozinsky-Glasberg S, Gueorguiev M: Activation of $\mathrm{RAF} / \mathrm{MEK} / \mathrm{ERK}$ and $\mathrm{PI} 3 \mathrm{~K} / \mathrm{AKT} / \mathrm{mTOR}$ pathways in pituitary adenomas and their effects on downstream effectors. Endoc Relat Cancer 16: 1329-1338, 2009

59) Cerovac V, Monteserin-Garcia J, Rubinfeld H, Buchfelder M, Losa M, Florio T, Paez-Pereda M, Stalla GK, Theodoropoulou M: The somatostatin analogue octreotide confers sensitivity to rapamycin treatment on pituitary tumor cells. Cancer Res 70:
666-674, 2010

60) Gorshtein A, Rubinfeld H, Kendler E, Theodoropoulou M, Cerovac V, Stalla GK, Cohen ZR, Hadani M, Shimon I: Mammalian target of rapamycin inhibitors rapamycin and RAD001 (everolimus) induce antiproliferative effects in GH-secreting pituitary tumor cells in vitro. Endocr Relat Cancer 16: 1017-1027, 2009

61) Jouanneau E, Wierinckx A, Ducray F, Favrel V, Borson-Chazot F, Honnorat J, Trouillas J, Raverot G: New targeted therapies in pituitary carcinoma resistant to temozolomide. Pituitary 15: 37-43, 2012

62) Vlotides G, Siegel E, Donangelo I, Gutman S, Ren SG, Melmed S: Rat prolactinoma cell growth regulation by epidermal growth factor receptor ligands. Cancer Res 68: 6377-6386, 2008

63) Fukuoka H, Cooper O, Ben-Shlomo A, Mamelak A, Ren SG, Bruyette D, Melmed S: EGFR as a therapeutic target for human, canine, and mouse ACTH-secreting pituitary adenomas. J Clin Invest 121: 4712-4721, 2011

Address reprint requests to: Toshio Hirohata, MD, Department of Neurosurgery, The University of Tokyo, 7-3-1 Hongo, Bunkyo-ku, Tokyo 113-8655, Japan. e-mail: hirohata-tky@umin.ac.jp 